Jeg hadde et tilsvar til ham i Tidsskriftet nr. 13-14/2011, der jeg klart gjorde rede for min agenda: Jeg ønsket å beholde retten til å kunne rekvirere medisiner til eget bruk (4). Jeg har aldri skrevet, sagt eller hatt noen mening hva gjelder fortsatt autorisasjon til å drive legepraksis o.l. Jeg stiller meg derfor undrende til at Tjensvoll fortsatt tillegger meg andre motiver enn dem jeg har og forfekter.

Lars Tjensvoll avsluttet sitt innlegg med at det det her dreier seg om, er at leger hjelper leger (1)!

Jeg er selvsagt takknemlig for at det finnes leger der ute som har påtatt seg å beskytte meg mot meg selv. Og at noen i den sammenheng har hjulpet meg med å miste retten til å rekvirere medisiner til eget bruk. Man kan aldri vite...

\section{Einar Skatteboe}

einskat@online.no
Einar Skatteboe (f. 1936) er pensjonert spesialist i samfunnsmedisin. Ingen oppgitte interessekonflikter.

\section{Litteratur}

1. Tjensvoll L. Behandle leger som piloter! Tidsskr Nor Legeforen 2012; 132: 2147.

2. Skatteboe E. Leger mot leger? Tidsskr Nor Legeforen 2012; 132: 1430

3. Tjensvoll L. Piloter og legelisens. Tidsskr Nor Legeforen 2011; 131: 2110-1.

4. Skatteboe E. Behandle oss som eldre piloter! Tidsskr Nor Legeforen 2011; 131 1278 .

Publisert som rask respons i nettutgaven 22.10. 2012

\title{
RETTELSE
}

Familiær forekomst av kronisk lymfatisk leukemi i Norge

Geir E. Tjønnfjord, Viggo Jønsson, Bernt E. Ly, Tom Børge Johannesen

Tidsskr Nor Legeforen 2012; 132: 2060-3

og

Kronisk lymfatisk leukemi i Norge -

insidens og prognose ved diagnosetidspunktet

Geir E. Tjønnfjord, Bernt E. Ly, Tom Børge Johannesen, Anne Tierens, Klaus Beiske, Sverre Heim, Viggo Jønsson

Tidsskr Nor Legeforen 2012; 132: 2056-9

I Tidsskriftet nr. 18/2012 side 2059 og 2063 har vi dessverre oppgitt kun navn på studiegruppe.
Gruppens deltakere er:

Jakob Dalgaard, Erwin Müller, Johannes Kahrs, Eystein Brandt, Petter Quist-Paulsen, Tom Fjornes, Kjell Sverre Galdal, Per Ole Iversen, Yngve Benestad, Jon Hjalmar Sørbø, Birgitte Dahl Eiken, Robert Brudevold, Yngve Sørum, Marit Rinde, Erik Blichfeldt, Clas Eika, Fredrik Schjesvold, Hoa Thi Tuyet Tran, Waleed Ghanima, Katarzyna Baronowska, Hedda Lerdal, Eva-Marie Jacobsen, Peter Meyer, Einar Haukås, Camilla Stapnes Bjørnsen, Eivind Galteland, Jann Bergheim, Tone Granseth, Vigdis Stenberg, Harald Torsvik, Håvar Knutsen, Johannes Barstad, Anders Waage, Jens Hammerstrøm, Astrid Bergrem, Inger Marie Dahl, Per Blichfeldt, Terje Løitegaard, Lidia Klevstul, Håkon Reikvam, Håvard Solhaug, Solveig Nilsen, Dag Ole Aanderbakk, Roald Lindås, Hildur Nordeng, Jørgen Ibsen, Tor Henrik A. Tvedt, Yngvar Fløisand, Eli Brevig, Steinar Jæger, Gunnar Hopen, Helene Negaard, Jon Lyng, Kjell Teigen, Øystein Fluge.

Vi beklager feilen, den er rettet i nettutgaven.

\section{RETTELSE}

Nevrografi ved karpaltunnelsyndrom

Kari Todnem, Trond Sand

Tidsskr Nor Legeforen 2013; 133: 171

I nr. 2/2013 side 171 skal benevningen i illustrasjonens midterste boks være: Langfinger $48 \mathrm{~m} / \mathrm{s}$, Lillefinger $59 \mathrm{~m} / \mathrm{s}$, Ringf.med $44 \mathrm{~m} / \mathrm{s}$ og Ringf.uln $63 \mathrm{~m} / \mathrm{s}$.

Vi viser her bare et utsnitt av figuren i rettet versjon. Figuren ligger rettet i sin helhet på nettet. Vi beklager feilen.

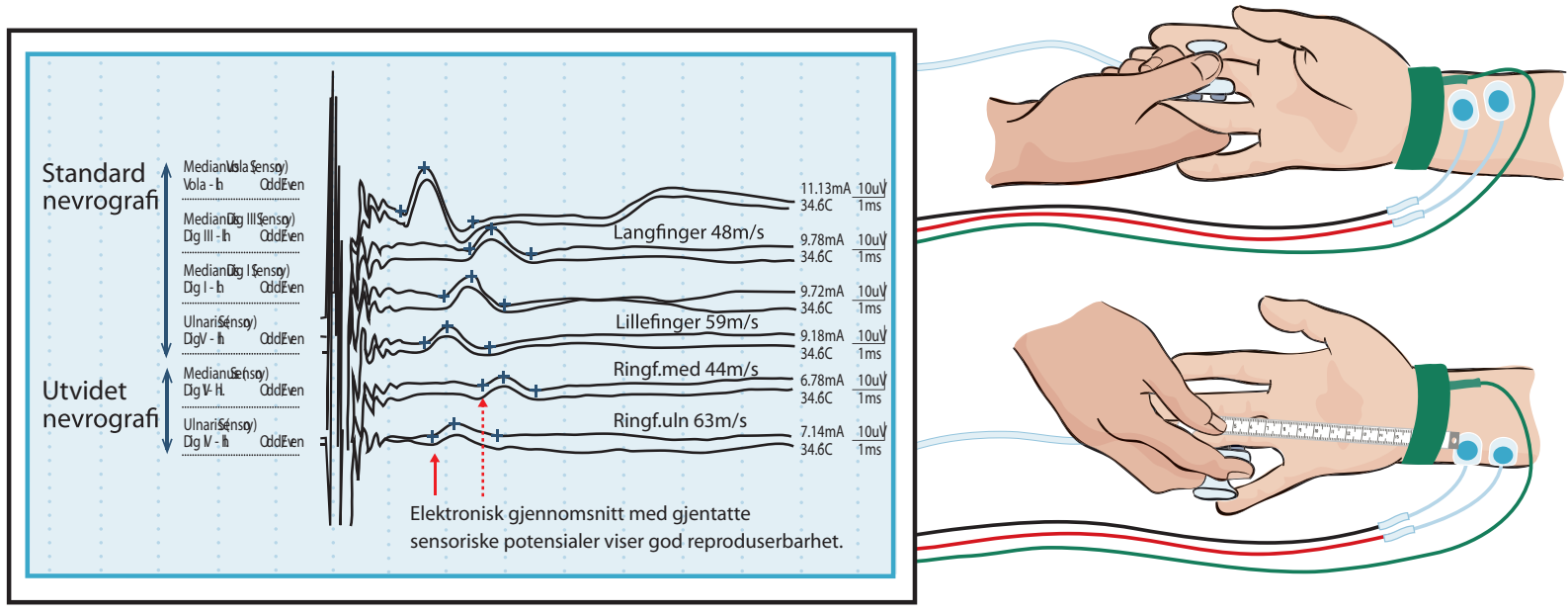

